\title{
Exploring the social acceptance of biomass power
}

\section{Kalle Nuortimo*}

Information and Communication Studies,

University of Oulu,

P.O. Box 4610, FI-90014, Finland

Email:kalle.nuortimo@amecfw.com

*Corresponding author

\section{Janne Härkönen}

Industrial Engineering and Management, University of Oulu, P.O. Box 4610, FI-90014, Finland

Email: janne.harkonen@oulu.fi

\section{Erkki Karvonen}

Information and Communication Studies, University of Oulu, P.O. Box 4610, FI-90014, Finland

Email:erkki.karvonen@oulu.fi

\begin{abstract}
Public acceptance and positive media image are among the key features in technology market deployment aside any technical, legal and economic questions. The way technologies appear in various forms of media has a tendency to shape the public acceptance. This study analyses the media image of biomass power in order to understand the recent technology developments needed to overcome global warming. The media sentiment is analysed from both editorial and social media by using M-adaptive tool for media monitoring. The analysis covers three million social media platforms, hundred thousand news outlets in over seventy languages over 236 regions covering a vast number of data points. The results indicate that the public sentiment towards biomass power is more positive in editorial publications than in the social media. It appears that the increasing role of social media for public acceptance may need to be acknowledged in technology deployment issues.
\end{abstract}

Keywords: social acceptance; biomass power; environmental review; media image; technology deployment; media monitoring tool.

Biographical notes: Kalle Nuortimo has been working in Amec Foster Wheeler since 2002 in technology, R\&D, marketing and communications related positions. His research focus is currently both energy technology R\&D and technology related public acceptance issues. 
Janne Harkonen received his Bachelor's degree (1st Class Honours) in Engineering Business Management from University of Greenwich in the UK and both his MSc in Process Engineering and Dr (Tech) in Industrial Engineering and Management, from the University of Oulu, Finland. He has also studied in the University of North Carolina at Wilmington, USA. He has experience working in the IT and environmental technology industries. Currently, he is a Senior Research Fellow at the University of Oulu in Finland. He has authored and co-authored over 40 journal articles, and also a number of other publications.

Erkki Karvonen is a Professor in Information and Communication Studies, University of Oulu.

\section{Introduction}

The need to reduce atmospheric $\mathrm{CO}_{2}$ has resulted in several global agreements (e.g., Kyoto Protocol, 1997; Paris Agreement, 2015). The fear of climate change has pushed governments around the world to commit to reducing their reliance on fossil energy and to increase the use of low carbon energy sources, including renewable energy (DevineWright, 2011). Simultaneously the public acceptance of these technologies is emphasised as crucial for the successful introduction of technologies into the society (Huijts et al., 2012). Electricity produced from biomass is one renewable option, generally providing favourable price, efficiency, emissions, and availability, but has often unfavourable high land and water usage as well as social impacts making the type and location of biomass growth vital to its sustainability (Evans et al., 2010). As a comparison, other solid fuel firing technologies and continuation of R\&D activities for clean coal technologies such as carbon capture and storage (CCS) is also seen as an alternative for near zero emission in power production. However, regardless of there being a large capacity of $\mathrm{CO}_{2}$ storage sites available globally, the public acceptance is largely affected by the possibility of $\mathrm{CO}_{2}$ leaking from the end storage. Hence, despite of techno-economic aspects, such as supply security favouring the technology market deployment in a large scale, and reaching near zero $\mathrm{CO}_{2}$ power production in the medium term of 10-20 years, the CCS market deployment has not advanced as the building of a commercial size oxyfuel demonstration power plant is delayed, also influenced by the public opinion (Santos, 2015).

Biomass-based power plants are the one of the few renewable energy sources (RES) that can be used as baseload technologies, contributing also to the reduction of external energy dependency, and to the greenhouse gas emissions (Carneiro and Ferreira, 2012). In fact, a study by Ahmad and Tahar (2014) found renewable energy resources to have potential to develop a true sustainable energy system, where solar power was seen as the most favourable resource followed by biomass. The public attitude, however can clearly influence the newbuilding of power plants as, for example, Upreti and van der Horst (2004) found that biomass projects fail due to two rigid characteristics among stakeholders, namely not-in-my-back-yard attitude by the public and the 'there-is-noalternative' attitude by developers. 
The future of bioenergy and biofuels seem to depend not only on the development of effective and efficient technologies, but also on the social, economic and political climate, in which people decide to use the new fuel sources and technologies (Wegener and Kelly, 2008). Biomass energy is particularly seen to require a collective effort by various actors (Upreti, 2004). Furthermore, the simultaneous increase in energy demand and the negative impact of fossil fuels on the environment emphasises the need to produce energy from RES and deploy relevant technologies (Stigka et al., 2014).

Today's market situation with increasing share of renewables, such as solar and wind, calls for fuel- and load-flexible technologies in biomass combustion, while maximum efficiency and economics of scale drive towards utility size solutions to the $300-\mathrm{MWe}$ scale and beyond with sole biomass fuels (Eriksson et al., 2016). At the end of 2014, there were approximately 2,900 active biomass power plants (without co-incinerators) throughout the world, having electricity generation capacity of approximately $47 \mathrm{GWel}$, and the capacity is expected to increase to around 4,250 power plants (about $71 \mathrm{GWel}$ ) by 2024, thus the worldwide support of renewable energies and the development of domestic energy sources are the most important reasons for this growth (Ecoprog, 2015).

As a result of ambitious targets that many governments have now adopted for increasing the deployment of renewable energy, systematic and robust social science research on public engagement with renewable energy is urgently required (DevineWright, 2014). This study provides its stake and analyses the media image of biomass power to provide understanding on the recent technology developments. The study utilises a methodology that enables a wider coverage and more data points than previous studies attempting to clarify media sentiments.

\section{Social acceptance of biomass power technologies}

On a social psychological level, individual behaviours are often guided by their attitudes and by the norms established by others within the social setting (Wegener and Kelly, 2008). In the past, some technologies have been connected with societal controversies, resulting in public rejection, further motivating to understand the psychological side of societal acceptance of technologies (Gupta et al., 2012). In addition, existing earlier examples of failed technology commercialisation indicate that the social acceptance can be a decisive factor for technology market deployment, and thus the early adoption of general public is essential (Ashworth et al., 2009). There has been a steady rise in the number of research finding determinants that have impacted the technology acceptance (Gupta et al., 2012). Renewable power is considered to be among the main existing technology options for near zero emission power production, one that is considered to be sustainable (Verbruggen, 2008). Nevertheless, Barry et al. (2008) suggest that key of the technological transition to a renewable energy economy has little to do with the technology itself, but with the public acceptability.

Various studies have recently investigated the acceptance of renewable power technologies. This while, to the detriment of social science input, the research and development on renewable energy has mainly focused on technological and economic approaches (Devine-Wright, 2014). The inclusion of key factors in technology acceptance have somewhat been missing (Huijts, et al. 2012). There has also been a tendency to generalise the character of opposition movements with shorthand labels such as not-in-my-backyard or 'NIMBY', without examining the reasons underlying the 
opposition (Firestone et al., 2012). Oxford English Dictionary (OED) defines NIMBY as "an attitude ascribed to persons who object to the siting of something they regard as detrimental or hazardous in their own neighbourhood, while by implication raising no such objections to similar developments elsewhere". In the light of the environmental psychology literature, the dominant model of contextualised values, intention and behaviour, as well as other psychological approaches are found to be helpful, both for making sense of the results and for informing a psychological research agenda on public objection to new energy infrastructure (Upham, 2009).

The literature explaining or describing the market penetration of renewable resources is growing, with mostly mainly three types of studies have been essential: those looking at national styles of regulation, those analysing the barriers to renewable energy, and those looking at the factors that drive local acceptance and opposition to renewable energy, often carried out by surveys on public attitudes and beliefs (Sovacool and Ratan, 2012). The positive overall acceptance for renewable energy has led researchers and policy makers to believe that public acceptance would not be an issue, while acceptance, like any social processes, is not static, but is subject to changes (Heras-Saizarbitoria et al., 2011). Hence, focusing only on acceptance and simultaneously ignoring relevant issues, such as support, resistance, apathy and uncertainty is a mistake, while, according to Batel et al. (2013), acceptance can be understood to justify, legitimise and reproduce top-down perspectives.

Sovacool and Ratan (2012) have proposed nine relevant factors for renewable electricity on the basis of socio-political, community, and market acceptance. Particularly those factors that influence socio-political and community acceptance are recognised ever more as important for understanding contradictions between public's support for renewable energy and the difficulties in realising specific projects (Wüstenhagen et al., 2007). Countries are seen to have a need to provide a combination of strong institutional capacity, political commitment, favourable legal and regulatory frameworks, competitive installation and/or production costs, mechanisms for information and feedback, access to financing, prolific community, and/or individual ownership and use, participatory project siting, and recognition of externalities or positive public image. The latter is in the main interest of this study. The presence of these factors is seen to increase the market acceptance, however, in countries where these conditions are lacking, the technology growth and diffusion is seen to slow down (Sovacool and Ratan, 2012). Nevertheless, it is the perceived benefits that have been found to have the greatest total effect on acceptability, whilst emerging as a key predictive factor of social acceptability of controversial electricity generation sources (Bronfman et al., 2012).

Concerning biomass power, positive attitudes have been found towards renewable energy, however, slightly less positive towards forest-based bio-energy (Qu et al., 2011). For example, a study on ninth grade students revealed more positive attitudes towards bio-energy compared to their perceptions. Students were positive about learning about bio-energy, but not about its utilisation (Halder et al., 2011). Zoellner et al. (2008) indicate that general support for renewable energies exists among the public, yet reaching further expansion of renewable energies utilisation require increasing support for concrete energy systems at local levels. Different factors can influence people's opinions, as for example Liu and Zhang (2012) indicate that positive intention increases with household income, individual knowledge level and beliefs about costs of renewable energy use, but decrease with individual age. As a link from public attitudes to policies, a 
major factor influencing public sentiment towards background policy conditions is risk perception, which can correlate to objective risks, increasing correspondingly with increasing hazard, however, it may also display non-correlative behaviours (McGuire, 2015). The literature seems to indicate positive general attitudes towards biomass power, which is further studied by analysing extensive data.

\section{Research methods}

The research methodology of this study consists of utilising a learning machine-based media analysis, carried out on a vast number of editorial and social media (SoMe) sources. In comparison with traditional news media, which can shape public opinion regarding an issue by emphasising some elements of the broader controversy over others (Shah et al., 2002), SoMe presents a more direct opinions, often including emotional content (Stieglitz and Dang-Xua, 2013). The basic research principles have been formerly applied in various fields of studies, for example, public acceptance studies have been made by the means of media analysis before, but with much smaller datasets. Also, sentiment analysis has been applied before, for example in marketing research. Media frames have also used together with cluster analysis and automated sentiment classification via software by Burscher et al. (2016). Hence, this study utilises the existing elements and extends the analysis to cover also SoMe aside the more traditional media in global analysis, thus remaining the comparability of datasets.

In this study, the application of for example framing and cluster analysis was considered to be non-applicable, in addition to statistical methods. This is due to comparison of editorial content with $\mathrm{SoMe}$, and to the fact that media frame comparability between two different types of communication is not possible, furthermore, at the same reason, it was also challenging to find suitable statistical method for data series analysis. The main reasons for choosing this method was applicability to large global datasets, both from editorial content and SoMe, fast data processing and reduced risk of bias caused by human perceptions and interpretations (Matthes and Kohring, 2008). Also, the SoMe has increased its significance as a data provider, making it an excellent platform for analysing public attitudes (Peñalver-Martinez et al., 2014). By utilising a learning machine, the quantity of analysed media sources is increased significantly compared to traditional questionnaires and interviews, or other means of media analysis. Merely relying on traditional qualitative methods would not allow a significant global media coverage, and responses would be difficult to code, while answers might vary by participants with a risk of receiving socially desired responses (Sovacool and Ratan, 2012). The analysis in this study is carried out to clarify the social acceptance status of biomass power technologies' in order to investigate the connection to recent increase in biomass power technology market deployment. The findings were synthesised to gain a clear view over the effect of social acceptance of biomass power technology development and market deployment. Hence, the research setting of this study is a modern media analysis with a large dataset. The data is studied to discover possible implications for public acceptance, political decision making and to find a link to technology market deployment.

The method utilised can be seen as a fairly new application in the public acceptance research. Opinion mining can be seen to be highly active field consisting of natural language processing, computational linguistics and text analysis technologies with a 
target to get various added value and informational elements from users' opinions (Peñalver-Martinez et al., 2014). This study is based on using a commercial software as the dramatic increase in number of online sources, including discussion forums, blogs and many other forms has resulted in a need to develop computational tools to analyse people's preferences and attitudes (Neviarouskaya et al., 2014). The role of media is highlighted as individuals and organisations are increasingly adopting public opinions through different forms of media when making their own decisions (Liu et al., 2013). To utilise the opinions, multiple systems have been constructed in an attempt to quantify opinions, for example from product reviews (Godbole et al., 2007), to predict financial markets (Nassirtoussi et al., 2014) aside more common marketing and brand follow-ups in the consumer-related manufacturing industry (Abrahams et al., 2013). The ability to gain fast access to customer experiences and feedback is highlighted (Ordenes et al., 2014), whereas the possibility to obtain nearly real-time information on public acceptance, can influence decision making processes and new policy creation in energy product market deployment and help targeting messaging for media.

The main research question in this paper is formulated as: what is the current media image of biomass power, both in editorial and SoMe, and how has this affected the technology market deployment. The main research method is learning machine systembased analysis, by utilising M-adaptive software. Similar type of method utilising automated sentiment classification was applied by Burscher et al. (2016). The analysed sources cover 3 million SoMe platforms, 100,000 news outlets in 71 languages in 236 regions (M-Brain). The sentiment analysis applied in this study is based on a combination of linguistic knowledge and human aided machine learning, which means that the software makes suggestions of classifications to humans, and humans then provide feedback on the correctness. Via this procedure the system learns to improve its classification of content into sentiment categories (M-Brain). The method can be considered more quantitative type of analysis compared to traditional methods such as surveys. The analysis was made by inputting the keyword 'biomass power plant' to Madaptive media monitoring software. The analysis was carried out on the time period of one year 2 July 2015 to 3 July 2016, including a total of 21,802 data points from both editorial $(15,730)$ publications and SoMe $(6,072)$.

In practice, the sentiment-coding expressions are first recognised among the analysed texts and automatically classified for type, e.g., positive terms or quantifying expressions. The amount and type of sentiments focused on the topic under analysis are then assessed; linking to the documents matching the topic, with the overall compound judgement displayed using five options: positive, negative, neutral, mixed and unknown. Even though Nasukawa and Yi (2003) implicate that the local sentiment might be more reliable than a global document sentiment, the human evaluators often fail to agree on the global sentiment on a document (Godbole et al., 2007). Also, human analysis of text information is subject to considerable biases, such as giving more attention to opinions in line with their own preferences (Liu et al., 2013). Hence, machine-based approach may prove beneficial.

Identifying semantic relationships between the sentiment expressions and the analysed topic is essential to improve the accuracy of the sentiment analysis (Nasukawa and Yi, 2003). At the moment, research focusing on sentiment analysis is estimated to be moving towards content, concept and context-based analysis of natural language text, in addition to applying time efficient parsing techniques suitable for big social data analysis 
(Cambria et al., 2013). The reliability of machine-based approaches has improved significantly as $80 \%$ of the sentiments are correct on average for a given document (MBrain), whilst it is possible that the system makes a mistake due to inherent ambiguity in natural language. Also, as for any artificial system, humour, sarcasm and irony are also beyond the system's abilities to understand. However, it is well known that humans do not agree $100 \%$ in similar tests either, making the machine-based approach reliable enough for analysis purposes. Additionally, catching the trends in the data becomes increasingly accurate with the increase in the amount of analysed documents, meaning that with large volumes the machine-based analysis qualitatively matches human judgement.

\section{Data analysis}

The data analysis included inputting the keyword 'biomass power plant' to M-adaptive media monitoring software. The analysis was carried out for the time period of 2 July 2015 to 3 July 2016, including a total of 21,802 data points from both editorial publications and SoMe sources. The SoMe had attracted almost three times less hits during the analysed period, compared to editorial media. This analysed period included also Paris agreement negotiations. This indicates that biomass power is not so widely discussed in the SoMe. Due to large amount of data, despite of some inaccuracy in machine-based analysis, the obtained dataset was adequate to further analyse the media image/sentiment. Figure 1 illustrates the sentiment towards biomass power both in editorial publications, and in SoMe.

Figure 1 Sentiment analysis - SoMe vs. editorial publications (see online version for colours)

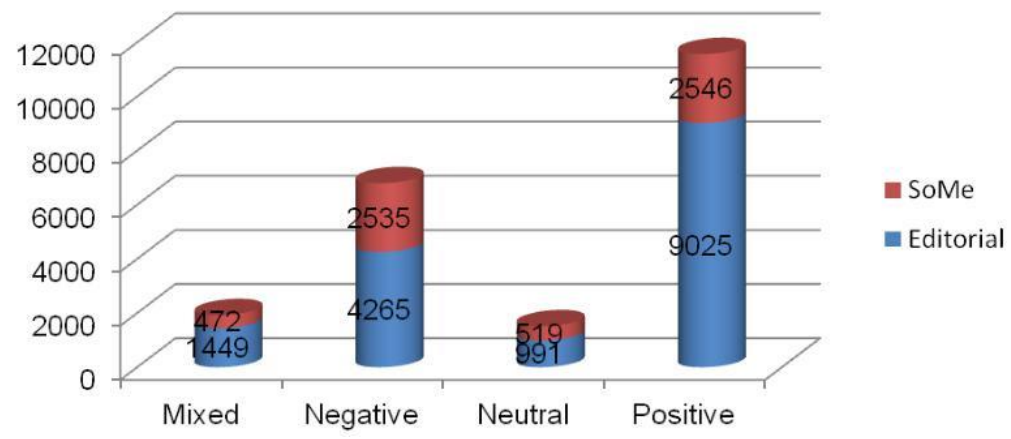

It can be seen from Figure 1 that the biomass power resulted mostly positive hits both in editorial publications, and also in the SoMe, however, the media image in SoMe is proportionally more negative than in the editorial content. This can be seen as an indication of strong positive editorial attitude, which indicate an extended exposure in editorial media channels.

It is clear that $58 \%$ of hits in editorial publications have been positive, and together with the share of neutral content, the general share rises to $64 \%$, thus indicating a relative high technology acceptance among the journalists, and also a slight absence of 
journalistic type of discussion and rhetoric's, which would include multiple views (Figure 2). The number of mixed (9\%) and neutral (6\%) hits is relatively small, indicating of a positive consensus towards biomass power in the editorial content.

Figure 2 Sentiment analysis of editorial publications (see online version for colours)

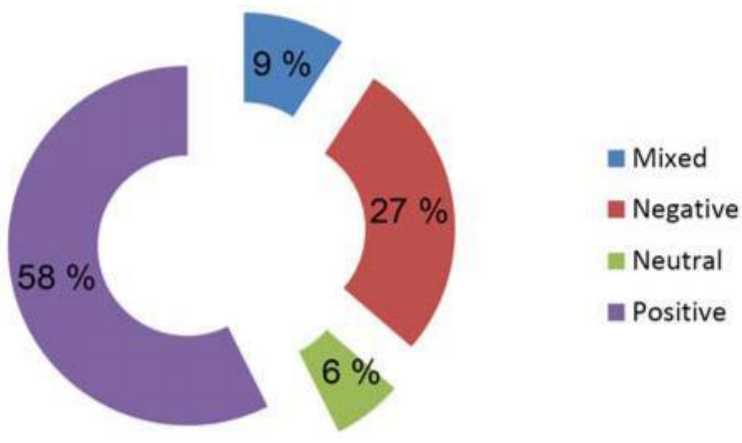

Nevertheless, the media sentiment is completely different when looking at the SoMe. It can be seen from Figure 3 that the public sentiment towards biomass power in the SoMe has been equally positive and negative with $42 \%$. This can be seen as indicator of more negative, split in attitudes amongst the lay people.

Figure 3 Biomass power's media sentiment in SoMe (see online version for colours)

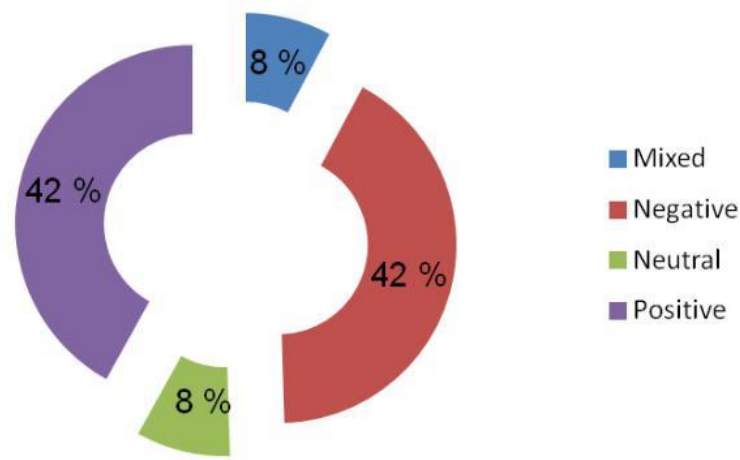

The deviation between sentiments in different SoMe sources is illustrated in Figure 4. It can be seen that blog writing has attracted most of the SoMe attention with over four thousand hits, writings which have mostly been negative towards biomass power $(2,029)$. The popularity of blog writing can be considered to be explained by the means to make more thorough statements on the issue, thus influencing more negative attitudes than in the editorial content. Due to over two times lower amount of SoMe hits, the SoMe effect can also be considered to be of a smaller influence in the case of biomass power. 
Figure 4 Deviation of SoMe sentiment by the media type (see online version for colours)

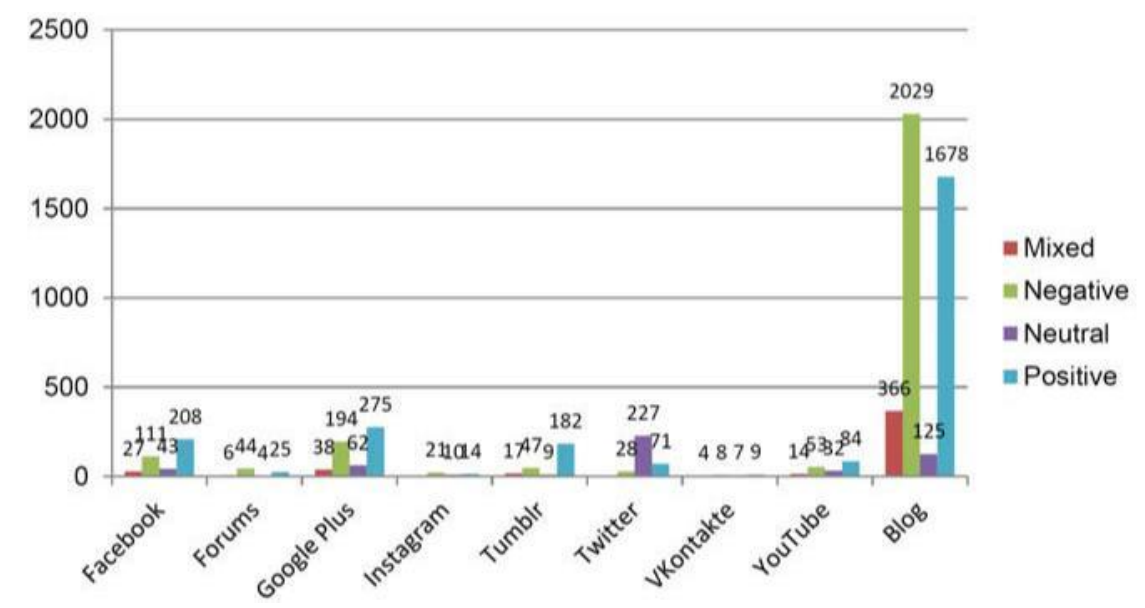

From Figure 5, it can be observed, that media sentiment has follower roughly also the biomass power plant new building in selected countries. Finland, have large utilisation of biomass power, has clearly less negative sentiments both in editorial content and in SoMe. Also Germany with renewable policies has positive editorial content, and SoMe had only one country identifiable negative comment.

Figure 5 Media sentiment in selected countries (see online version for colours)

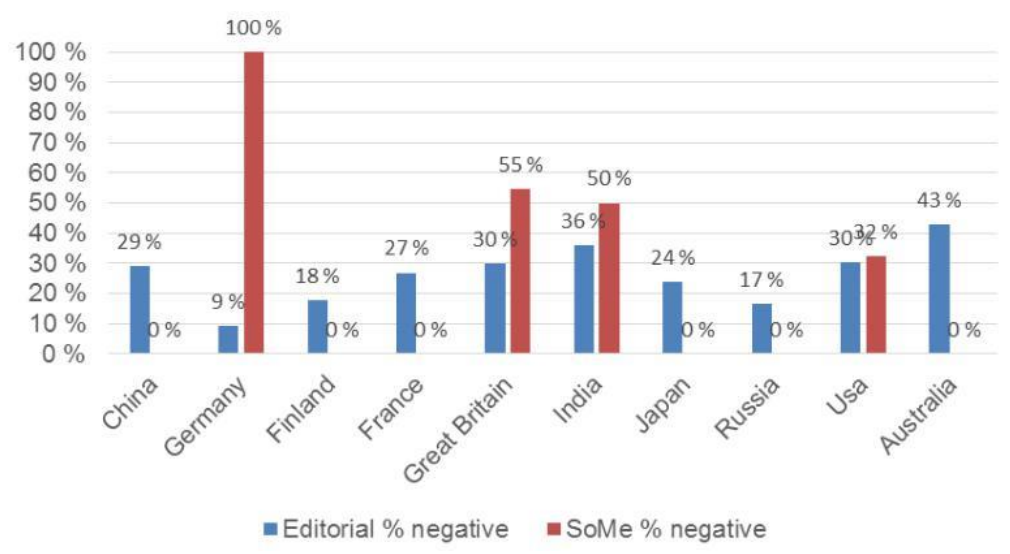

The effect of global climate negotiations on the media image of biomass power is illustrated in Figure 6, where the impact of Paris COP negotiations on editorial publications and SoMe is shown. The preliminary conclusion that is possible to be drawn includes biomass power technology's media image being rather neutral, and slightly different during the time of the large global climate conference compared the entire analysis period. The share of neutral editorial coverage was larger compared to the entire analysis period with $67 \%$ over $6 \%$, whereas the figures for positive $11 \%$ over $58 \%$, and $20 \%$ over $27 \%$ significantly. For SoMe, $77 \%$ of writings were neutral during the Paris COP compared to $8 \%$ over the entire analysis period, whereas $13 \%$ of writings were positive over $42 \%$, and $10 \%$ negative over $42 \%$ during the entire period. This indicates 
that significant international events have at least a temporary influence on the media sentiment.

Figure 6 Media attention during Paris COP21 negotiations (see online version for colours)

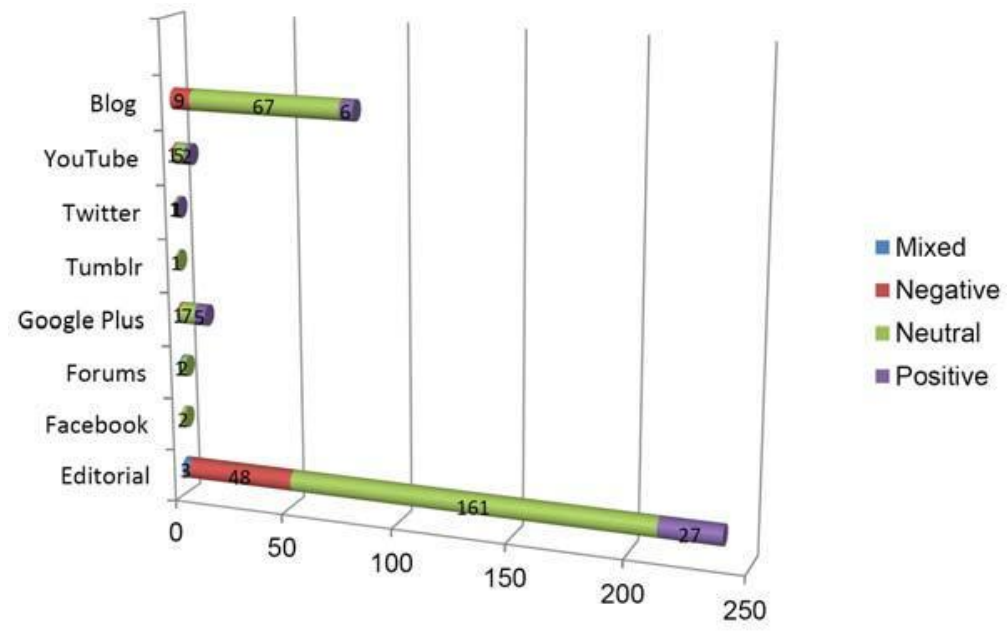

\section{Discussion}

The global media analysis on the media sentiment of biomass power was carried out by utilising the M-adaptive software for media monitoring. The analysis was made for an entire years' worth of media feed including a total of 21,802 data points from both editorial publications and SoMe. The total media sentiment relating to biomass power was found to be generally positive in both editorial content and in SoMe, where the editorial sources included more positive attitudes. Active discussions on the topic have also taken place in the SoMe. For example, biomass power is discussed in a variety of blogs with over 4,000, mostly negative hits $(2,029)$. Hence, from the perspective of biomass power market deployment, it seems that the more positive SoMe content a technology could obtain in the future, the better. When considering the effect of relevant international events such as the global climate negotiations, Paris COP 21, the media attention seems to have somewhat neutralised towards the biomass power, thus not largely influencing the market deployment of relevant technologies.

Nevertheless, regional differences influence on deployment of biomass power. This is further proved by country analysis, which indicates correlation between biomass power plant newbuilding, and media sentiment in each country. Good examples of this correlation include Finland and Germany with positive attitudes and also newbuilding of biomass power. This represents one general point of concern in the data validity for making generalisations. In addition, despite the global agreements, biomass power plant technology commercialisation itself is largely influenced by regional politics and legislation. Thus, it is to be noted, that local NIMBY attitudes are not so clearly visible when using the approach utilised in this study. Local differences may influence the potential construction of biomass power plants in single cases. However, the main benefit 
of obtaining a global media sentiment and using a large data set lies in obtaining better understanding over global trends and technology development directions. Also, understanding the differences in various channels of communication may prove beneficial if attempting to influence the public acceptance and political decision making. Improved understanding of existing media sentiment is valuable when understanding different types of attitudes in editorial publications and in the SoMe. The role of SoMe is continuously increasing, and presents challenges for technology developers in the light of public acceptance. The data seems to indicate that a positive link for biomass power, from editorial writings to public acceptance, economics and policies to technology market deployment may exists. This however seems not to be the case for SoMe, at least not as strongly.

The main contributions of this study include presenting an example of the utilisation of a method, more typical in marketing research, on a study on biomass power public acceptance. Therefore, this study provides a possible new angle to related media and social acceptance issues. The approach is rather new compared to several questionnaires, or interview-based studies with moderate datasets with some hundreds of data points, e.g., Heras-Saizarbitoria et al. (2011). The method may have positive and negative sides, when compared to traditional qualitative studies, however, could provide a strong basis for longitudinal data series analyses, a feature somewhat missing in the previous studies.

The findings of this study confirm the previous findings of the media sentiment on biomass power being positive in general (e.g., Zoellner et al., 2008; Halder et al., 2011). This study, however has obtained the global media sentiment on biomass power over the analysis period of one year with a vast number of data points. This is new to the previous research. Opposite to previous studies, this study has also included analysing the global media sentiment in the SoMe, providing also the unedited true opinion of the regular people, something that is not typically present in the edited content. This study also confirms the findings by Heras-Saizarbitoria et al. (2011) in the media sentiment not being static but being subject to changes, this is evident by the influence of Paris COP on the media sentiment.

The managerial implications of this paper are mainly related to biomass power investment related public acceptance issues, including focus on research method developments. The method used in this study has the potential of being applied for revealing global attitudes from editorial content and the SoMe. Also, the changes in global attitudes towards technologies for example during the time of international events are possible to be clarified. Managers planning for biomass power projects may benefit from the results of this study by understanding the urgency for public engagement, and the need for SoMe participation.

The limitations of this study include the analysed media sentiment being limited to those classifications possible with the used keywords; hence, the results might be slightly different if using alternative keywords. In addition, framing, cluster analysis and other statistical methods were found challenging to apply, otherwise the comparability between editorial content and SoMe could have been lost. Consequently, although statistical techniques are widely used among communication scholars to identify news frames, they are criticised for not being able to do so in a conceptually valid manner (Carragee and Roefs, 2004). This presents also challenge to further research. Also, when comparing to qualitative methods such as those used by Sovacool and Ratan (2013), research interviews might possess some advantages, including possible facilitation of a more complete flow of knowledge when the answers are not confined to the responses and 
categories anticipated by the researcher. This might help in dealing with value laden and subjective issues. Furthermore, no content analysis was committed due to a large dataset. The sentiment analysis, however, was also tested by human with random testing, agreeing with accuracy of app. $80 \%$ indicated by software provider. Also, this study does not reveal the local differences in the media sentiment, ones that have value when considering more local technology deployment and project planning.

\section{Conclusions}

This study clearly indicates that biomass power production has generally a positive public image, which is further emphasised during large national climate congresses such as the Paris COP21. Biomass power is seen to benefit from the positive image and public acceptance, however, the image is clearly more negative in the SoMe indicating a lower level of acceptance. The general image however, appears as positive in contrast to some other more controversial technologies. Factors favouring biomass power market deployment include its availability as a baseload capacity, sustainability and $\mathrm{CO}_{2}$ emissions.

The media analysis indicates that biomass power has attracted much positive and neutral attention in both, editorial content and in SoMe at a global level, thus it also seems to correlate to newbuilding in respective country. The SoMe can particularly be seen to have a new role in influencing the acceptance of biomass power technology in a positive way. However, the SoMe may require more attention due to the larger amount of negative hits than the editorial contents. There seems to be a connection, indicated by reviewing data on a country level, between the public acceptance and the global biomass power deployment, related politics and regulations. This is clearly evident also in the light of the increased biomass power capacity, which is currently taking place.

\section{References}

Abrahams, A.S., Jiao, J., Fan, W., Wang, G.A. and Zhang, Z. (2013) 'What's buzzing in the blizzard of buzz? Automotive component isolation in social media postings', Decision Support Systems, Vol. 55, No. 4, p.871.

Ahmad, S. and Tahar, R.M. (2014) 'Selection of renewable energy sources for sustainable development of electricity generation system using analytic hierarchy process: a case of Malaysia', Renewable Energy, Vol. 63, pp.458-466.

Ashworth, P., Boughen, N., Mayhew, M. and Millar, F. (2009) 'An integrated roadmap of communication activities around carbon capture and storage in Australia and beyond', Energy Procedia, Vol. 1, No. 1, pp.4749-4756.

Barry, J., Ellis, G. and Robinson, C. (2008) 'Cool rationalities and hot air: a rhetorical approach to understanding debates on renewable energy', Global Environmental Politics, Vol. 8, No. 2, pp.67-98.

Batel, S., Devine-Wright, P. and Tangeland, T. (2013) 'Social acceptance of low carbon energy and associated infrastructures: a critical discussion', Energy Policy, Vol. 58, pp.1-5.

Bronfman, N.C., Jiménez, R.B., Arévalo, P.C. and Cifuentes, L.A. (2012) 'Understanding social acceptance of electricity generation sources', Energy Policy, Vol. 46, pp.246-252.

Burscher, B., Vliegenthart, R. and de Vreese, C. (2016) 'Frames beyond words: applying cluster and sentiment analysis to news coverage of the nuclear power issue', Social Science Computer Review, Vol. 34, No. 5, pp.530-545. 
Cambria, E., Schuller, B., Xia, Y. and Havasi, C. (2013) 'New avenues in opinion mining and sentiment analysis', IEEE Intelligent Systems, Vol. 28, No. 2, pp.15-21.

Carneiro, P. and Ferreira, P. (2012) 'The economic, environmental and strategic value of biomass', Renewable Energy, Vol. 44, No. 3, pp.17-22.

Carragee, K.M. and Roefs, W. (2004) 'The neglect of power in recent framing research', Journal of Communication, Vol. 54, No. 2, pp.214-233.

Devine-Wright, P. (2011) Renewable Energy and the Public From NIMBY to Participation, Earthscan, Routledge, Oxon, UK, ISBN: 978-1-84407-863-9.

Devine-Wright, P. (2014) Renewable Energy and the Public: From NIMBY to Participation, Routledge, Oxon, New York, NY, ISBN: 978-1-84407-863-9.

Ecoprog (2015) [online] http://www.ecoprog.com/ (accessed 14 August 2016).

Eriksson, T., Barišić, V., Kovács, J., Nuortimo, K. and Jäntti, T. (2016) 'State of the art CFB technology paving the way to utility size production with versatile solid ebiomass fuel supply', PowerGen Europe 2016.

Evans, A., Strezov, V. and Evans, T.J. (2010) 'Sustainability considerations for electricity generation from biomass', Renewable and Sustainable Energy Reviews, Vol. 14, No. 5, pp.1419-1427.

Firestone, J., Kempton, W., Lilley, M.B. and Samoteskul, K. (2012) 'Public acceptance of offshore wind power: does perceived fairness of process matter?', Journal of Environmental Planning and Management, Vol.55, No. 10, pp.1387-1402.

Godbole, N., Srinivasaiah, M. and Skiena, S. (2007) 'Large-scale sentiment analysis for news and blogs', ICWSM, Vol. 7, No. 21, pp.219-222.

Gupta, N., Fischer, A.R.H. and Frewer, L.J. (2012) 'Socio-psychological determinants of public acceptance of technologies: a review', Public Understanding of Science, Vol. 21, No. 7, pp.782-795.

Halder, P., Havu- Nuutinen, S., Pietarinen, J. and Pelkonen, P. (2011) 'Bio-energy and youth: analyzing the role of school, home, and media from the future policy perspectives', Applied Energy, Vol. 88, No. 4, pp.1233-1240.

Heras-Saizarbitoria, I., Cilleruelo, E. and Zamanillo, I. (2011) 'Public acceptance of renewables and the media: an analysis of the Spanish PV solar experience', Renewable and Sustainable Energy Reviews, Vol. 15, No. 9, pp.4685-4696.

Huijts, N.M.A., Molin, E.J.E. and Steg, L. (2012) 'Psychological factors influencing sustainable energy technology acceptance: a review-based comprehensive framework', Renewable and Sustainable Energy Reviews, Vol. 16, No. 1, pp.525-531.

Liu, B. and Zhang, L. (2012) 'A survey of opinion mining and sentiment analysis', Mining Text Data, pp.415-463, Springer.

Liu, W., Wang, C. and Mol, A.P.J. (2013) 'Rural public acceptance of renewable energy deployment: the case of Shandong in China', Applied Energy, Vol. 102, pp.1187-1196.

Matthes, J. and Kohring, M. (2008) 'The content analysis of media frames: toward improving reliability and validity', Journal of Communication, Vol. 58, pp.258-279.

M-Brain, Corporate Communications, received 11/2015.

McGuire, C.J. (2015) 'The role of risk perception in building sustainable policy instruments: a case study of public coastal flood insurance in the USA', Interdisciplinary Environmental Review, Vol. 16, Nos. 2-4, pp.232-252.

Nassirtoussi, A.K., Aghabozorgi, S., Ying Wah, T. and Ngo, D.C.L. (2014) 'Text mining for market prediction: a systematic review', Expert Systems with Applications, Vol. 41, No. 16, pp.7653-7670, doi:10.1016/j.eswa.2014.06.009.

Nasukawa, T. and Yi, J. (2003) 'Sentiment analysis: capturing favorability using natural language processing', Proceedings of the 2nd International Conference on Knowledge Capture, pp.7077. 
Neviarouskaya, A., Aono, M., Predinger, H. and Ishizuka, M. (2014) 'Intelligent interface for textual attitude analysis', ACM Transactions, Vol. 5, No. 3, Article 48.

Ordenes, F.V., Theodoulidis, B., Burton, J., Gruber, T. and Zaki, M. (2014) 'Analyzing customer experience feedback using text mining: a linguistics-based approach', Journal of Service Research: JSR, Vol. 17, No. 3, p.278.

Peñalver-Martinez, I., Garcia-Sanchez, F., Valencia-Garcia, R., Rodríguez-García, M.Á., Moreno, V., Fraga, A. and Sánchez-Cervantes, J.L. (2014) 'Feature-based opinion mining through ontologies', Expert Systems with Applications, Vol. 41, No. 13, pp.5995-6008, doi:10.1016/j.eswa.2014.03.022.

Qu, M., Ahponen, P., Tahvanainen, L., Gritten, D., Mola-Yudego, B. and Pelkonen, P. (2011) 'Chinese university students' knowledge and attitudes regarding forest bio-energy', Renewable and Sustainable Energy Reviews, Vol. 15, No. 8, pp.3649-3657.

Santos, S. (2015) 'Oxy-CFB combustion technology, it's potential role in CO2-mitigation', O2GEN Workshop, 18 June, Turku, Finland.

Shah, D.V., Watts, M.D., Domke, D. and Fan, D.P. (2002) 'News framing and cueing of issue regimes: explaining Clinton's public approval in spite of scandal', Public Opinion Quarterly, Vol. 66, No. 3, pp.339-370.

Sovacool, B. and Ratan, P.L. (2012) 'Conceptualizing the acceptance of wind and solar electricity', Renewable and Sustainable Energy Reviews, Vol. 16, No. 7, pp.5268-5279.

Stieglitz, S. and Dang-Xuan, L. (2013) 'Emotions and information diffusion in social media sentiment of microblogs and sharing behavior', Journal of Management Information Systems, Vol. 29, No. 4, pp.217-248.

Stigka, E.K., Paravantis, J.A. and Mihalakakou, G.K. (2014) 'Social acceptance of renewable energy sources: a review of contingent valuation applications', Renewable and Sustainable Energy Reviews, Vol. 32, pp.100-106.

Upham, P. (2009) 'Applying environmental-behaviour concepts to renewable energy siting controversy: reflections on a longitudinal bioenergy case study', Energy Policy, Vol. 37, No. 11, pp.4273-4283.

Upreti, B.R. (2004) 'Conflict over biomass energy development in the United Kingdom: some observations and lessons from England and Wales', Energy Policy, Vol. 32, No. 6, pp.785800.

Upreti, B.R. and van der Horst, D. (2004) 'National renewable energy policy and local opposition in the UK: the failed development of a biomass electricity plant', Biomass and Bioenergy, Vol. 26, No. 1, pp.61-69.

Verbruggen, A. (2008) 'Renewable and nuclear power: a common future?', Energy Policy, Vol. 36, No. 11, pp.4036-4047.

Wegener, D.T. and Kelly, J.R. (2008) 'Social psychological dimensions of bioenergy development and public acceptance', Bioenergy Research, Vol. 1, No. 2, pp.107-117.

Wüstenhagen, R., Wolsink, M. and Bürer, M.J. (2007) 'Social acceptance of renewable energy innovation: an introduction to the concept', Energy Policy, Vol. 35, No. 5, pp.2683-2691.

Zoellner, J., Schweizer-Ries, P. and Wemheuer, C. (2008) 'Public acceptance of renewable energies: results from case studies in Germany', Energy Policy, Vol. 36, No. 11, pp.41364141 . 